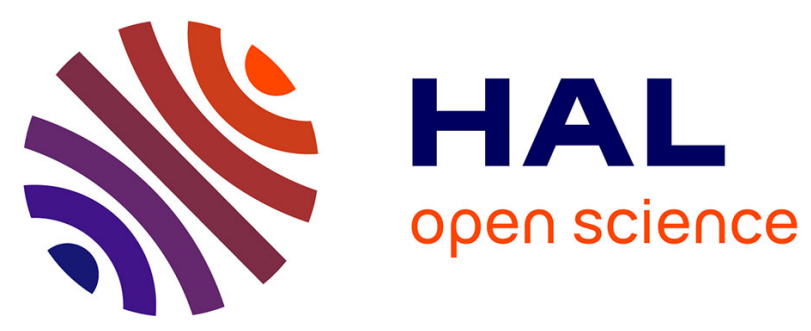

\title{
Evaluation of a tube-based constitutive equation using conventional and planar elongation flow optical rheometers
}

Ghalia Boukellal, Audrey Durin, Rudy Valette, Jean-François Agassant

\section{- To cite this version:}

Ghalia Boukellal, Audrey Durin, Rudy Valette, Jean-François Agassant. Evaluation of a tube-based constitutive equation using conventional and planar elongation flow optical rheometers. Rheologica Acta, 2011, 50 (5-6), pp.547-557. 10.1007/s00397-011-0573-y . hal-00612051

\section{HAL Id: hal-00612051}

https://hal-mines-paristech.archives-ouvertes.fr/hal-00612051

Submitted on 28 Jul 2011

HAL is a multi-disciplinary open access archive for the deposit and dissemination of scientific research documents, whether they are published or not. The documents may come from teaching and research institutions in France or abroad, or from public or private research centers.
L'archive ouverte pluridisciplinaire HAL, est destinée au dépôt et à la diffusion de documents scientifiques de niveau recherche, publiés ou non, émanant des établissements d'enseignement et de recherche français ou étrangers, des laboratoires publics ou privés. 


\title{
Evaluation of a tube based constitutive equation using conventional and planar elongation flow optical rheometers
}

\author{
Ghalia Boukellal · Audrey Durin · Rudy Valette · Jean-François \\ Agassant
}

Received: date / Accepted: date

\begin{abstract}
The predictions of the Marrucci and Ianniruberto model (2003) have been studied in various rheometric flows as well as a planar elongation flow using the 'optical elongational rheometer' technique proposed by Schuberth and Münstedt (2008). This combination of techniques extended the range of pertinence of the model to high extensional rates. Relevance of the identified parameters with respect to tube theory was then discussed.
\end{abstract}

Keywords Planar elongational flows - Birefringence Laser-Doppler velocimetry - Tube based constitutive equations

\section{Introduction}

Since the advent of the Doi and Edwards (1986) theory, tube based constitutive equations for polymer melts have been increasingly successful in predicting linear rheometric flows for both monodisperse and polydisperse linear entangled melts, together with providing a clear link between their macromolecular characteristics and model parameters.

Further constitutive models have then been introduced in order to correct the shortcomings of the initial

This paper is dedicated to Professor Helmut Münstedt, Friedrich-Alexander Universität Erlangen-Nürnberg on the occasion of his $70^{\text {th }}$ birthday.

\section{R. Valette}

Mines ParisTech, CEMEF - Centre de Mise en Forme des Matériaux

CNRS UMR 7635

BP 207, 1 rue Claude Daunesse

06904 Sophia Antipolis Cedex, France

Tel.: +33-4 93678903

Fax: +33492389752

E-mail: rudy.valette@mines-paristech.fr theory, particularly in 'strong', nonlinear rheometric flows such as fast elongational flows (Bach et al. 2003). These advanced models include, for example (Ianniruberto and Marrucci 2001; Likhtman and Graham 2003; Marrucci and Ianniruberto 2003), chain stretch and convective constraint release.

The pertinence of advanced models to predict complex flows of monodisperse and polydisperse melts has been studied using various experimental approaches, coupled with numerical solution procedures. In these studies, different flow geometries such as contraction, contraction-expansion slit or cross-slot were investigated, for moderately 'strong' flows, as follows. First an a priori model parameter identification was performed. This was peformed using linear and nonlinear (mainly elongational) rheometry, coupled with a suitable optimization procedure to compute the values of the many model parameters. Then, 2D or 3D numerical simulations were performed and compared to experimental measurements using flow-induced birefringence (FIB) in recent studies (Lee et al. 2001; Collis et al. 2005; Valette et al. 2006; Hassell et al. 2008; Hassell et al. 2009; Scelsi et al. 2009; Auhl et al. 2011) or both FIB and laser-Doppler velocimetry (LDV) in earlier ones (Schoonen et al. 1998; Peters et al. 1999; Agassant et al. 2002; Verbeeten et al. 2002; Verbeeten et al. 2004; Gough et al. 2008). Most of the cited studies have shown that a rather good agreement could be obtained.

However, apart for linear monodisperse melts in recent studies, a theoretically-based link (or missing link) between polymer melts characteristics and nonlinear model parameters was not discussed a priori. Moreover, in the recent studies, which involved the most advanced constitutive models, only FIB experimental patterns were compared to computed FIB patterns (Lee et al. 2001; Collis et al. 2005; Valette et al. 2006; Hassell et 
al. 2008; Hassell et al. 2009; Scelsi et al. 2009; Auhl et al. 2011). Consequently it was not possible to check consistency between measured velocity and resulting FIB patterns.

In this study, comparison of experimental and computed FIB pattern was proposed using an alternative approach. In this approach, LDV measurements were performed to obtain velocity and velocity gradients on the symmetry axis of a smooth contraction flow and then used to compute FIB patterns from the tubebased model of Marrucci and Ianniruberto (2003). This approach was inspired by the work of Schuberth and Münstedt (2008), who developped an 'optical elongational rheometer' for polymer fluids of low viscosity, following earlier studies of Quinzani et al. (1994) and Quinzani et al. (1995). Prior to this comparison, dynamic, capillary and elongational measurements at a wide range of temperatures and deformation rates were performed. A preliminary parameter identification is then proposed and discussed in terms of relevance to molecular theory. Computed stress field were then compared with the one experimentally measured using FIB. In order to reduce the discrepancy between experimental and numerical stress field some nonlinear parameters of the constitutive equation were modified. Consistency between these new parameters and preliminary rheometrical measurement was finally checked .

\section{Polymer and Rheometry}

In this paper a commercial grade Polystyrene (Styron ${ }^{\mathrm{TM}}$ 648 from the Dow Chemical Company) was used. Molecular characteristics of PS 648 are listed on table 1.

The complex modulus is measured (using a Rheometric Scientific ARES 600) at various temperatures. The WLF equation (parameters table 2) allows to obtain a master curve for the complex modulus (figure 1) and for the complex viscosity (figure 2).

Capillary measurements were obtained on a Gottfert Rheotester 1000 using several dies $(1 \mathrm{~mm}$ in diameter and various $L / D$ ratios: $10,20,30)$ for Bagley corrections (Macosko 1994). Weissenberg-Rabinowitsch corrections (Macosko 1994) allowed to deduce the viscosity as a function of the true shear rate. Capillary measurements were superimposed with dynamic measurements (see figure 2), which were consistent with Cox and Merz observations (Macosko 1994). A Newtonian plateau is observed at low shear rates, then a classical power-law decrease of the viscosity, followed by a change of slope above $500 \mathrm{~s}^{-1}$ which could anticipate a second Newtonian plateau at higher shear rates.

Elongational viscosity measurements were performed on a Meissner (1972) RME rheometer at $180^{\circ} \mathrm{C}$ for elon- gational rates ranking between $0.16 s^{-1}$ and $1 s^{-1}$ (figure 3). The transient elongational viscosity followed the linear regime for short times and the lowest rates. For longer times and higher rates, the elongational viscosity deviated from the linear regime and then reached a maximum before sample breakage. The plateau just before breakage could eventually be considered as a 'stationary elongational viscosity' (Bach et al. 2003).

\section{Constitutive equation and preliminary identification}

Previous rheometry data were used to fit a set of multimode Marrucci and Ianniruberto model (2003) parameters. This tube model, which was originally proposed in a single mode version, includes several mechanisms for both tube orientation relaxation such as reptation, constraint release (Doi and Edwards 1986), convective constraint release -CCR- (Ianniruberto and Marrucci 1996) and chain stretch relaxation (Doi and Edwards 1986), that occur at different time scales. To overcome the shortcomings of previous models where orientation and stretch were decoupled (Ianniruberto and Marrucci 2001; Wapperom et al. 2003), this model was built using an 'undecoupled' (Marrucci and Ianniruberto 2003) equation for tube conformation tensor $\mathbf{C}$ :

$\dot{\mathbf{C}}=\nabla \mathbf{v} \mathbf{C}+\mathbf{C} \nabla \mathbf{v}^{T}-\frac{f}{\Theta}\left(\mathbf{C}-\frac{I_{\mathbf{C}}}{3} \mathbf{I}\right)-\frac{1}{3 \theta_{r}}\left(f I_{\mathbf{C}}-1\right) \mathbf{I}(1)$

where $\nabla \mathbf{v}$ and $\mathbf{I}$ are the velocity gradient and unit tensors, $I_{\mathbf{C}}$ the trace of $\mathbf{C}, \Theta$ and $\theta_{r}$ the orientation and stretch relaxation times, and $f$ is the finite extensibility factor.

Orientation time $\Theta$ is defined as:

$\frac{1}{\Theta}=\frac{1}{\theta}+\left(\frac{1}{\theta_{r}}-\frac{1}{\theta}\right) \frac{\beta\left(f I_{\mathbf{C}}-1\right)}{1+\beta\left(f I_{\mathbf{C}}-1\right)}$

where $\theta$ is half of the reptation only disengagement time and $\beta$ is a numerical CCR parameter of order 1 (Marrucci and Ianniruberto 2003), governing the transition of $\Theta$ from $\theta$ (slow flows) to $\theta_{r}$ ('strong' flows).

The finite extensibility factor $f$ is defined as:

$f=\frac{b-1}{b-I_{\mathbf{C}}}$

where $b$ has the meaning of the square of the maximum stretch ratio. For polystyrene, Dhole et al. (2003) suggested that $b=66$, whereas Rolón-Garrido et al. (2006) proposed a maximum stretch ratio of 5 , which implies $b=25$.

Finally the polymeric stress tensor is defined:

$\boldsymbol{\tau}=3 G f\left(\mathbf{C}-\frac{1}{3} \mathbf{I}\right)$ 
where $\mathrm{G}$ is the elastic modulus, which is around $2 \times$ $10^{5} \mathrm{~Pa}$ for polystyrene (Dhole et al. 2003). For this study a 'crude' multimode extension of the Marrucci and Ianniruberto model for polystyrene was investigated. This model is able to capture qualitatively the main features which have been experimentally observed in the preceding section: Newtonian plateau, shear thinning effect as well as nonlinear behaviour in elongation.

A 8 modes relaxation spectrum was first identified from the dynamic data (figure 1) using the non linear regression method early proposed by Baumgaertel and Winter (1989) (table 3).

For each mode, the three non linear parameters, $\beta$, $\theta_{r}$ and $b$ were then identified. For all set of parameters, it was found that the stationary shear viscosity curve was mainly sensitive to the parameter $\beta$, as expected (Ianniruberto and Marrucci 1996). The value $b=66$, as prescribed by Dhole et al. (2009) for each mode was used as a starting parameter for the identification. Finally, a simplified form of classical scaling theories (Doi and Edwards 1986; Likhtman and McLeish 2002) was used to determine $\theta_{r}$ :

$\theta_{r_{i}}=\theta_{e}\left(\frac{\theta_{r_{i}}}{\theta_{e}}\right)^{\frac{2}{3}}$

where $\theta_{e}$ would correspond to the relaxation time for a macromolecular chain with only one entanglement. This relaxation time was choosen of the order of the inverse frequency corresponding to the end of the rubberry plateau $\left(10^{-5} s\right.$ on figure 1$)$.

Using these three non linear parameters $(\beta=1$, $b=66, \theta_{e}=10^{-5} s$ ) led to a reasonable agreement for the shear viscosity but not for the uniaxial elongational viscosity (figure 4). A better fit for stationary shear viscosity was obtained by decreasing the CCR parameter $\beta$ to 0.92 , strain hardening was obtained by increasing the exponent of equation (5) $\left(\frac{2.44}{3}\right.$ instead of $\left.\frac{2}{3}\right)$ and decreasing the finite extensibility parameter $b$ to $b_{i}=(10,10,10,10,10,10,20,30)$ from the fastest to slowest mode (figure 5). These values are more consistent with the ones prescribed in Rolón-Garrido et al. (2006). It should be noted however that the more accurate fit was obtained using a non unique value of $b$ for each mode. It should also be noticed that elongational results at low strain rates could exhibit measurement errors (Rolón-Garrido et al. 2006), which would explain the discrepancy at low elongational rates.

\section{Velocity and stress field measurements}

We used a single screw extruder Kaufman (screw diameter $40 \mathrm{~mm}$ ) coupled with a servo controlled gear pump to obtain a constant and controlled flow rate within a partially transparent die. This die was made of a semi circular converging geometry (Combeaud et al. 2004). The reservoir had a square section $(14 \mathrm{~mm} \times 14 \mathrm{~mm})$ and the final slit gap was $1 \mathrm{~mm}$ thick and $20.75 \mathrm{~mm}$ long (figure 6). Transparent Pyrex ${ }^{\circledR}$ glass windows on each side of the die allowed to analyse carefully the flow field.

A laser doppler Dantec velocity measurement technology was used. In this study we focused on the velocity field in the mid plane of the die and on the symmetry axis. The precision of laser Doppler velocity measurements is higher on the symmetry axis than at the wall, and typical $1 \%$ precision was obtained for each point after 1 min sampling time (Hertel, 2008). A complete set (for all investigated flow rates) of velocity and birefringence measurement required a few hours and several $\mathrm{kg}$ of polymer. Figure 7 shows velocity plotted for several flow rates ranging from $0.05 \mathrm{~g} / \mathrm{s}$ to $0.7 \mathrm{~g} / \mathrm{s}$. Velocity was approximated using a high order polynomial fit and then elongational rates could be computed as shown on figure 8 . For the largest flow rate, the elongational rate reached values as high as $18 s^{-1}$.

The optical set-up for FIB measurements (Robert et al. 2003; Robert et al. 2004) used a monochromatic sodium source (wave length $\lambda=589 \mathrm{~nm}$ ). An initial polarizer filter, a first $1 / 4$ wave plate, positioned at $45^{\circ}$ from the direction of polarization eliminated isoclinic fringes interfering with isochromatic fringes. On the other side of the transparent slit die, a second $1 / 4$ wave plate compensated for modifications in total birefringence produced by the first plate. A final analyser filter enabled the observation of chromatic birefringence fringes in the flow field.

The transverse aspect ratio in the reservoir and the slit were, respectively, 1 and 14 . While three-dimensional effects may arise in low aspect ratio regions (Wales, 1976), it was shown by Clemeur et al. (2004) that these effects may not have a great impact on the observed birefringence. Consequently, it is reasonable to consider that the principal stress difference may be related to the order $k$ of the isochromatic extinction lines by:

$\boldsymbol{\sigma}_{1}-\boldsymbol{\sigma}_{2}=\frac{k \lambda}{C W}$

where $C$ is the stress optical coefficient and $W$ the die width. On the symmetry axis $\boldsymbol{\sigma}_{1}=-p+\boldsymbol{\tau}_{x x}$ and $\boldsymbol{\sigma}_{2}=-p$ which means that we had directly access to the polymeric stress component in the flow direction. The value of $C=-4.010^{-9} \mathrm{~Pa}^{-1}$ at $180^{\circ} \mathrm{C}$ was taken from Han and Drexler (1973) and Macosko (1994). For the conditions probed, a high number of fringes were observed, which were in part due to the high value of the stress optical coefficient (figure 9). Using a dedicated image analysis (which consisted in finding the set 
G. Boukellal et al.

of local maxima of grey levels) allowed to detect precisely the position of each isochromatic line, and so the $k$ value from which we obtained the stress component in the flow direction (figure 10). According to the stressoptical law, we observed elongational stress values as high as $10^{6} \mathrm{~Pa}$. However, it was shown by Venerus et al. (1999) and Luap et al. (2005) that linearity in the stress optical law failed beyond a certain stress value around $10^{6} \mathrm{~Pa}$ (which may vary depending on sample polydispersity). In Venerus et al. (1999), Luap et al. (2005) and Rolón-Garrido et al. (2006), departure from linearity was clearly explained by the role played by finite extensibility effects: at high elongational rates, stress increases faster than 'FIB stress'. Consequently, for model - experiments comparisons in the following, we computed 'corrected FIB stresses' from the Marrucci and Ianniruberto model by dropping the finite extensibility term $f$ for each mode in equation 4 . We then used a 'computed corrected FIB stress' $\tau^{\prime}$ defined as:

$\boldsymbol{\tau}^{\prime}=3 G\left(\mathbf{C}-\frac{1}{3} \mathbf{I}\right)$

\section{New identification step}

As the proposed convergent flow geometry induced non uniform and high planar elongational rates, it was used to test the pertinence of both the constitutive equation and parameters identified previously. The general principle of the identification procedure was based on using the flow field measurements on the symmetry axis and the computed planar elongational rate as input parameters in the Marrucci and Ianniruberto constitutive equation, together with the previously identified linear and nonlinear viscoelastic parameters.

'Corrected elongational FIB stress' distribution on the axis in the flow direction was then computed using equation 7 for each investigated flow rate, and compared to the one measured using flow birefringence. On figure 11 we observed that the agreement was qualitatively fair, but the computed corrected FIB stresses were overestimated at high elongational rates and underestimated at low elongational rates. Origins of the observed discrepancies could be two fold: first, FIB patterns integrated 3D effects especially in the reservoir, second, the parameters of the constitutive equation were identified in slow rheological flow conditions, with constant shear rates and elongational rates, which were different from those presented in figures 7 and 10 .

We then revisited the identifying procedure accounting for these new field experiments; relaxation spectrum were obviously keep constant ; CCR parameter were slightly increased (0.95 instead of 0.92$)$; finite extensibility coefficient $b$ were modified (smaller values for the three fastest modes) and $\theta_{e_{i}}$ has been changed to $5 \times 10^{-4}$ for the three fastest modes. A line search method was used to minimize the quadratic distance between all measured and computed curves. The step size was restricted to 0.01 for the CCR parameter, 1 to the finite extensibility coefficient $b$ and 0.01 to the exponent of equation 5. As a result of these changes, the final agreement for the 12 different flow rates was much improved especially at high rates (figure 12). The identified parameters are listed table 4 .

The last step consisted in checking that the steady shear and elongational viscosity curves were still well predicted using these new parameters, which was found to be the case (figure 13).

\section{Discussion and conclusion}

This study was a first attempt to test the validity of constitutive equations and to identify their non linear parameters using both conventional and optical rheometry for polymer melts. It was shown that optical elongational rheometry could extend the conventional rheometry measurement window in two ways: it extends the range of investigated strain rates and it provides additional data in non uniform planar elongation. Moreover, it was shown that a simple multimode tube-based model (Marrucci and Ianniruberto 2003) could predict most of the experimental resuls using a set of theoreticaly addmissible set of parameters, apart for some finite extensibility parameters that needed to be set to unrealistically small values.

The next step would be to measure velocity andFIB along the flow axis of the downstream channel and to check the relevance of the constitutive equation in that domain. In fact, most of the constitutive equations which give reasonable agreement for stress build up are less relevant for stress relaxation (Wapperom et al. 2005).

In a second step the whole velocity and birefringence fields may be considered. On each streamline, the balance between elongational and simple shear would be different and this would represent a more severe test for the constitutive equations. It would be first necessary to check the validity of the experiments and especially the 3D effects generated by the shape factor of the upstream reservoir (Hertel et al. 2008, Sirakov et al. 2005) and the boundary conditions along the two side glass windows. In a second step $3 \mathrm{D}$ viscoelastic computations need to be performed with selected constitutive equations at high rates (Dhole et al. 2009; Likhtman and Graham 2003; Wagner et al. 2005; Wagner et al. 2008). 


\section{References}

Agassant JF, Baaijens F, Bastian H, Bernnat A, Bogaerds ACB, Coupez T, Debbaut B, Gavrus AL, Goublomme A, van Gurp M, Koopmans RJ, Laun HM, Lee K, Nouatin OH, Mackley MR, Peters GWM, Rekers G, Verbeeten WMH, Vergnes B, Wagner MH, Wassner E, Zoetelief WF (2002) The matching of experimental polymer processing flows to viscoelastic numerical simulation. International Polymer Processing 17:3-10

Auhl D, Hoyle DM, Hassell D, Lord TD, Mackley MR, Harlen OG, McLeish TCB (2011) Cross-slot extensional rheometry and the steady-state extensional response of long chain branched polymer melts. Journal of Rheology 55:875-900

Bach A, Rasmussen HK, Hassager O (2003) Extensional viscosity for polymer melts measured in the filament stretching rheometer. Journal of Rheology 47:429-441

Baumgaertel M, Winter HH (1989) Determination of discrete relaxation and retardation time spectra from dynamic mechanical data. Rheologica Acta 28:511519

Clemeur N, Rutgers RPG, Debbaut B (2004) Numerical evaluation of three dimensional effects in planar flow birefringence. J. Non-Newtonian Fluid Mech 123 105-120

Collis MW, Lele AK, Mackley MR, Graham RS, Groves DJ, Likhtman AE, Nicholson TM, Harlen OG, McLeish TCB, Hutchings LR, Fernyhough CM, Young RN (2005) Constriction flows of monodisperse linear entangled polymers: Multiscale modeling and flow visualization. Journal of Rheology 49:501-522

Combeaud C, Demay Y, Vergnes B (2004) Experimental study of the volume defects in polystyrene extrusion. Journal of Non-Newtonian Fluid Mechanics 121:175-185

Dhole S, Leygue A, Bailly C, Keunings R (2009) A single segment differential tube model with interchain tube pressure effect. Journal of Non-Newtonian Fluid Mechanics 161:10-18

Doi M, Edwards SF (1986) The theory of polymer dynamics. Oxford University Press, New York

Gough T, Spares R, Kelly AL, Brook SM, Coates PD (2008) Three-dimensional characterisation of full field stress and velocity fields for polyethylene melt through abrupt contraction. Plastics Rubber and Composites 37:158-165

Han CD and Drexler LH (1973) Studies of converging flows of viscoelastic polymeric melts. I. Stressbirefringent measurements in the entrance region of a sharp-edged slit die. J. Appl. Polymer Sci, 17:23292354

Hassell DG, Auhl D, McLeish TCB, Mackley MR (2008) The effect of viscoelasticity on stress fields within polyethylene melt flow for a cross-slot and contractionexpansion slit geometry. Rheologica Acta 47:821834

Hassell DG, Mackley MR (2009) An experimental evaluation of the behaviour of mono and polydisperse polystyrenes in Cross-Slot flow. Rheologica Acta 48: 543-550

Hassell DG, Hoyle D, Auhl D, Harlen O, Mackley MR, McLeish TCB (2009) Effect of branching in crossslot flow: the formation of 'W cusps'. Rheologica Acta 48:551-561

Hertel D (2008) Flow of polyethlene melts within and into rectangular ducts investigated by laser Doppler velocimetry. PhD Thesis, Friedrich-Alexander- Universität, Erlangen-Nürnberg

Hertel D, Valette R, Münstedt H (2008) Three dimensional entrance flow of a low-density polyethylene (LDPE) and a linear low-density polyethylene (LLDPE) into a slit die. Journal of Non-Newtonian Fluid Mechanics 153:82-94

Ianniruberto G, Marrucci G (1996) On compatibility of the Cox-Merz rule with the model of Doi and Edwards. Journal of Non-Newtonian Fluid Mechanics 65:241-246

Ianniruberto G, Marrucci G (2001) A simple constitutive equation for entangled polymers with chain stretch. Journal of Rheology 45:1305-1318

Lee K, Mackley MR, McLeish TCB, Nicholson TM, Harlen OG (2001) Experimental observation and numerical simulation of transient "stress fangs" within flowing molten polyethylene. Journal of Rheology 45:1261-1277

Likhtman AE, McLeish TCB (2002) Quantitative theory for linear dynamics of linear entangled polymers. Macromolecules 35:6332-6343

Likhtman AE, Graham RS (2003) Simple constitutive equation for linear polymer melts derived from molecular theory: Rolie-Poly equation. Journal of Non-Newtonian Fluid Mechanics 114:1-12

Luap C, Muller C, Schweizer T, Venerus DC (2005) Simultaneous stress and birefringence measurements during uniaxial elongation of polystyrene melts with narrow molecular weight distribution. Rheologica Acta 45:83-91

Macosko CW (1994) Rheology Principles, Measurements and Applications. VCH Publishers, New York Marrucci G, Ianniruberto G (2003) Flow-induced orientation and stretching of entangled polymers. Philosophical Transactions of the Royal Society of Lon- 
don Series A-Mathematical Physical and Engineering Sciences 361:677-687

Meissner J (1972) Development of a universal extensional rheometer for uniaxial extension of polymer melts. Transactions of the Society of Rheology 16:405420

Peters GWM, Schoonen JFM, Baaijens FPT, Meijer HEH (1999) On the performance of enhanced constitutive models for polymer melts in a cross-slot flow. Journal of Non-Newtonian Fluid Mechanics 82:387427

Quinzani LM, Armstrong RC, Brown RA (1994) Birefringence and Laser-Doppler velocimetry (LDV) studies of viscoelastic flow through a planar contraction. Journal of Non-Newtonian Fluid Mechanics 52:1-36

Quinzani LM, Armstrong RC, Brown RA (1995) Use of coupled birefringence and LDV studies of flow through a planar contraction to test constitutive equations for concentrated polymer solutions. Journal of Rheology 39:1201-1228

Robert L, Demay Y, Vergnes B (2004) Stick-slip flow of high density polyethylene in a transparent slit die investigated by laser Doppler velocimetry. Rheologica Acta 43:89-98

Robert L, Vergnes B, Demay Y (2003) Flow birefringence study of the stick-slip instability during extrusion of high-density polyethylenes. Journal of NonNewtonian Fluid Mechanics 112:27-42

Rolón-Garrido VH, Wagner MH, Luap C, Schweizer T (2006) Modeling non-Gaussian extensibility effects in elongation of nearly monodisperse polystyrene melts. Journal of Rheology 50:327-340

Scelsi L, Mackley MR, Klein H, Olmsted PD, Graham RS, Harlen OG, McLeish TCB (2009) Experimental observations and matching viscoelastic specific work predictions of flow-induced crystallization for molten polyethylene within two flow geometries. Journal of Rheology 53:859-876

Schoonen JFM, Swartjes FHM, Peters FPT, Meijer HEH (1998) A 3D numerical/experimental study on a stagnation flow of a polyisobutylene solution. Journal of Non-Newtonian Fluid Mechanics 79:529561

Schuberth S, Münstedt H (2008) Simultaneous measurements of velocity and stress distributions in polyisobutylenes using laser-Doppler velocimetry and flow induced birefringence. Rheologica Acta 47:111-119

Sirakov I, Ainser A, Haouche M, Guillet J (2005) Threedimensional numerical simulation of viscoelastic contraction flows using the Pom-Pom differential constitutive model. Journal of Non-Newtonian Fluid Mechanics 126:163-173
Valette R, Mackley MR, del Castillo GHF (2006) Matching time dependent pressure driven flows with a Rolie Poly numerical simulation. Journal of NonNewtonian Fluid Mechanics 136:118-125

Verbeeten WMH, Peters GWM, Baaijens FPT (2002) Viscoelastic analysis of complex polymer melt flows using the eXtended Pom-Pom model. Journal of NonNewtonian Fluid Mechanics 108:301-326

Verbeeten WMH, Peters GWM, Baaijens FPT (2004) Numerical simulations of the planar contraction flow for a polyethylene melt using the XPP model. Journal of Non-Newtonian Fluid Mechanics 117:73-84

Venerus DC, Zhu S-H, Öttinger HC (1999) Stress and birefringence measurements during the uniaxial elongation of polystyrene melts. Journal of Rheology 43:795-813

Wagner MH, Kheirandish S, Hassager O (2005) Quantitative prediction of transient and steady-state elongational viscosity of nearly monodisperse polystyrene melts. Journal of Rheology 49:1317-1327

Wagner MH, Rolón-Garrido VH, Nielsen JK, Rasmussen HK, Hassager O (2008) A constitutive analysis of transient and steady-state elongational viscosities of bidisperse polystyrene blends. Journal of Rheology 52:67-86

Wales JLS (1976) The Application of Flow Birefringence to Rheological Studies of Polymer Melts. PhD Thesis, Delft University of Technology, Delft

Wapperom P, Keunings R, Ianniruberto G (2003) Prediction of rheometrical and complex flows of entangled linear polymers using the double-convection reptation model with chain stretch. Journal of Rheology 47:247-265

Wapperom P, Leygue A, Keunings R (2005) Numerical simulation of large amplitude oscillatory shear of a high-density polyethylene melt using the MSF model. Journal of Non-Newtonian Fluid Mechanics 130:63-76 
Table 1 Molecular characteristics of PS 648

\begin{tabular}{llllll}
\hline $\begin{array}{l}\text { Density } \\
\text { at } 23^{\circ} \mathrm{C} \\
\left(10^{3} \mathrm{~kg} \cdot \mathrm{m}^{-3}\right)\end{array}$ & $\begin{array}{l}\text { Density } \\
\text { at } 200^{\circ} \mathrm{C} \\
\left(10^{3} \mathrm{~kg} \cdot \mathrm{m}^{-3}\right)\end{array}$ & $\begin{array}{l}\text { Number-averaged } \\
\text { molecular mass } M_{n} \\
\left(\mathrm{~kg} \cdot \mathrm{mol}^{-1}\right)\end{array}$ & $\begin{array}{l}\text { Weight-averaged } \\
\text { molecular mass } M_{w} \\
\left(\mathrm{~kg} \cdot \mathrm{mol}^{-1}\right)\end{array}$ & $\begin{array}{l}\text { Z-averaged } \\
\text { molecular mass } M_{z} \\
\left(\mathrm{~kg} \cdot \mathrm{mol}^{-1}\right)\end{array}$ & $\begin{array}{l}\text { Glass transition } \\
\text { temperature } \\
\left({ }^{\circ} \mathrm{C}\right)\end{array}$ \\
\hline 1.047 & 0.973 & 136 & 296 & 460 & 100 \\
\hline
\end{tabular}

Table 2 Coefficients of the WLF equation for PS 648

\begin{tabular}{lll}
\hline$C_{1}$ & $\begin{array}{l}C_{2} \\
\left({ }^{o} K\right)\end{array}$ & $\begin{array}{l}T_{0} \\
\left({ }^{o} C\right)\end{array}$ \\
\hline 5.02 & 122.4 & 180 \\
\hline
\end{tabular}

Table 3 Relaxation spectrum for PS 648 at $180^{\circ} \mathrm{C}$

\begin{tabular}{ll}
\hline$\theta_{i}(s)$ & $G_{i}(\mathrm{~Pa})$ \\
\hline $7.6310^{-3}$ & $8.8610^{4}$ \\
$1.0810^{-1}$ & $5.3510^{4}$ \\
$6.7210^{-1}$ & $2.0910^{4}$ \\
1.35 & $1.0810^{5}$ \\
4.93 & $8.4010^{3}$ \\
$1.7010^{1}$ & $1.7110^{3}$ \\
$3.8110^{1}$ & $5.0210^{2}$ \\
$1.7910^{2}$ & $9.3110^{1}$ \\
\hline
\end{tabular}

Table 4 Parameters identified at $180^{\circ} \mathrm{C}$ for the Marrucci and Ianniruberto constitutive equation

\begin{tabular}{lllll}
\hline$\theta_{i}(s)$ & $G_{i}(P a)$ & $\beta$ & $\theta_{r_{i}}(s)$ & $b$ \\
\hline $7.6310^{-3}$ & $8.8610^{4}$ & 0.95 & $2.0010^{-3}$ & 5 \\
$1.0810^{-1}$ & $5.3510^{4}$ & 0.95 & $1.6910^{-2}$ & 5 \\
$6.7210^{-1}$ & $2.0910^{4}$ & 0.95 & $7.2810^{-2}$ & 5 \\
1.35 & $1.0810^{5}$ & 0.95 & $1.2710^{-1}$ & 10 \\
4.93 & $8.4010^{3}$ & 0.95 & $3.5810^{-1}$ & 10 \\
$1.7010^{1}$ & $1.7110^{3}$ & 0.95 & $9.6510^{-1}$ & 10 \\
$3.8110^{1}$ & $5.0210^{2}$ & 0.95 & 1.60 & 20 \\
$1.7910^{2}$ & $9.3110^{1}$ & 0.95 & 5.52 & 30 \\
\hline
\end{tabular}




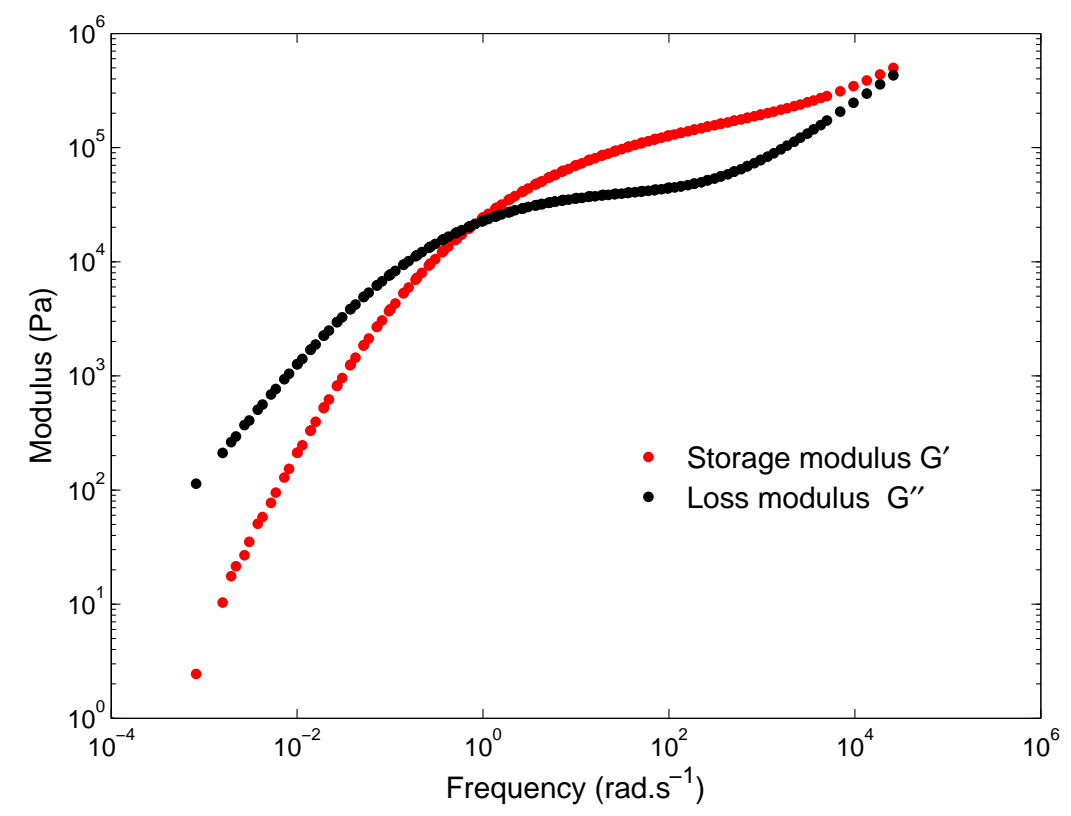

Fig. 1 Master curves of the complex modulus at $180^{\circ} \mathrm{C}$

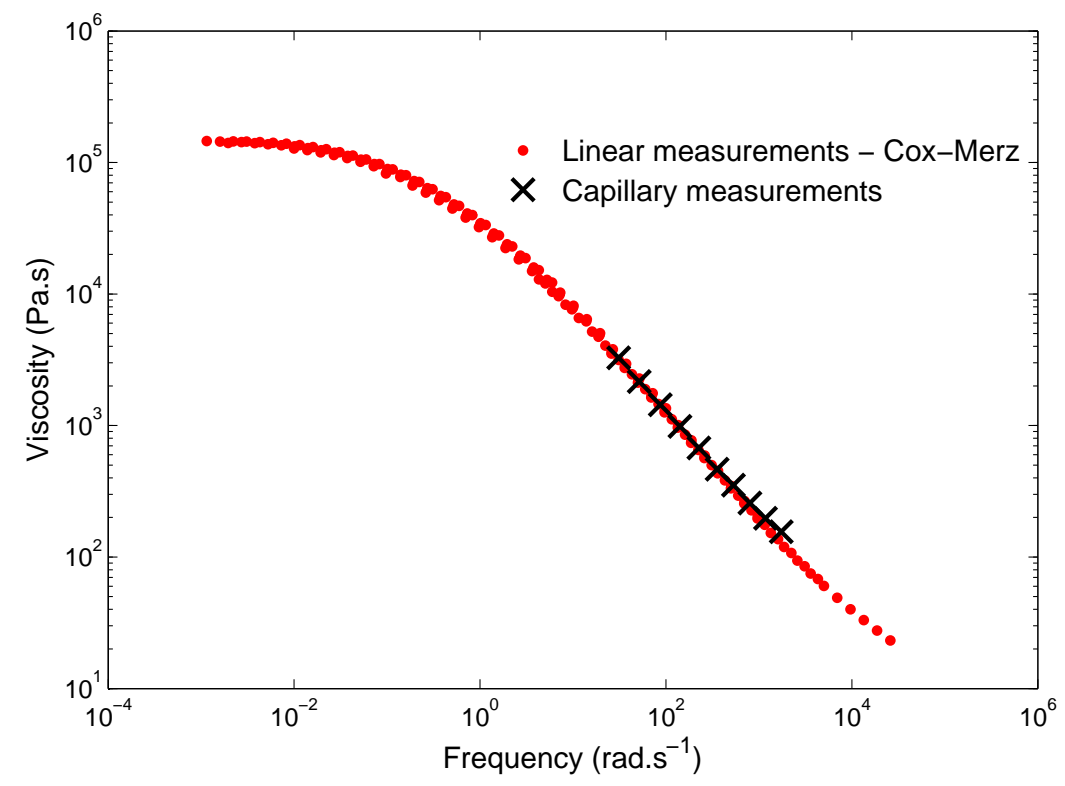

Fig. 2 Master curves of the complex viscosity at $180^{\circ} \mathrm{C}$, capillary viscosity measurements are superimposed 


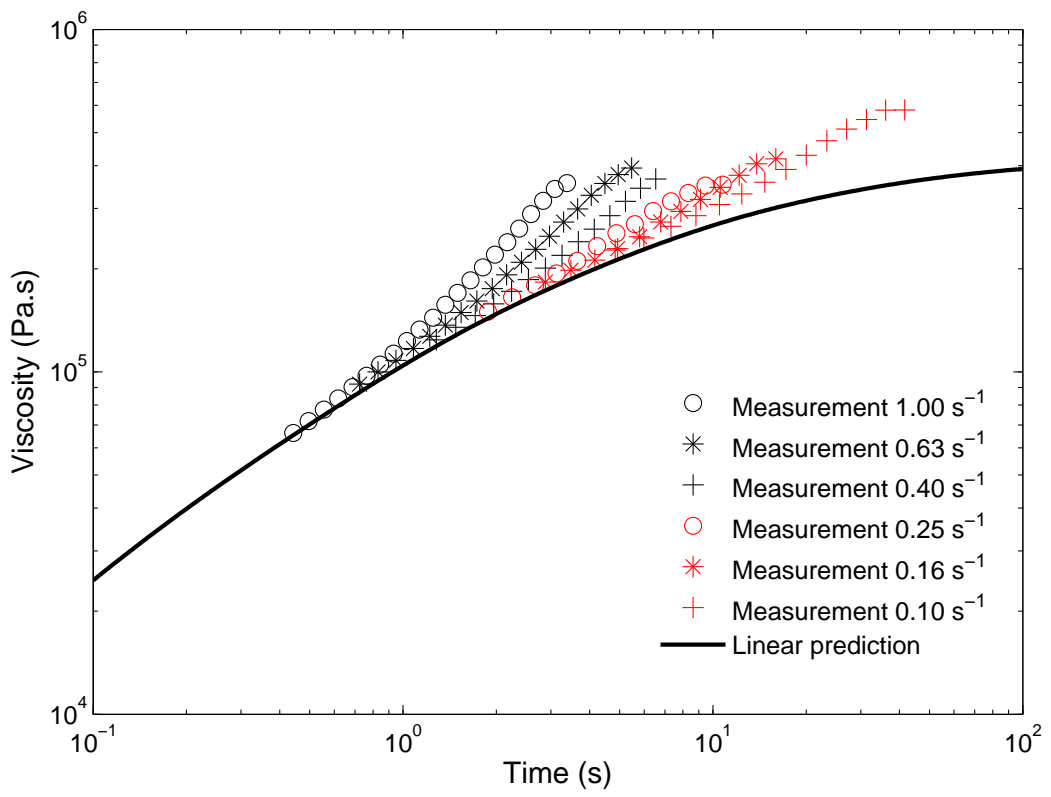

Fig. 3 Uniaxial elongation viscosity as a function of time for various elongation rates at $180^{\circ} \mathrm{C}$ 


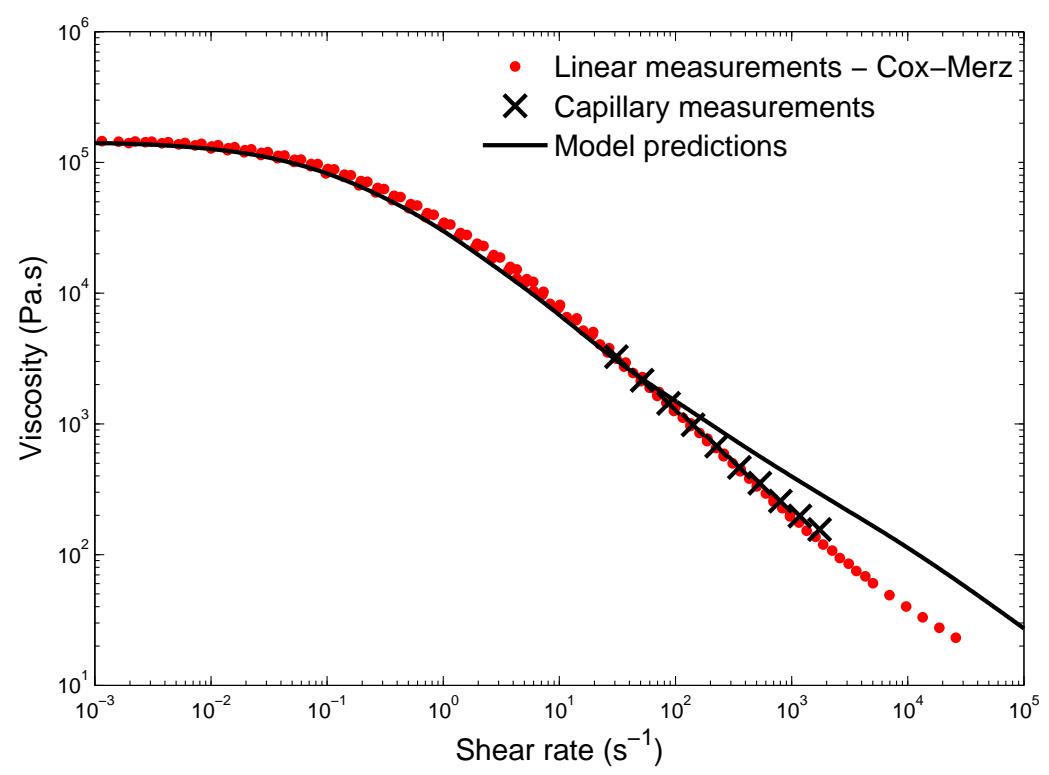

a)

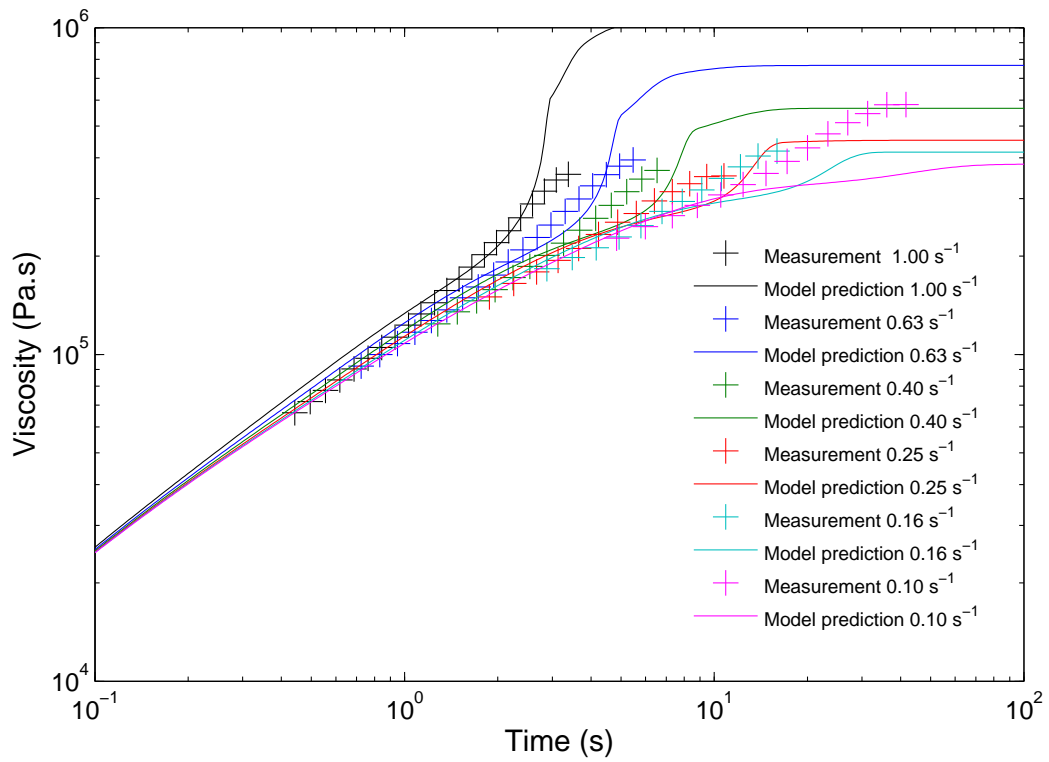

b)

Fig. 4 First set on non linear parameters $\left(\beta=1, b=66, \theta_{e}=10^{-5} s\right)$, comparison between experimental and computed viscosity: (a) steady shear behaviour, (b) elongational viscosity 


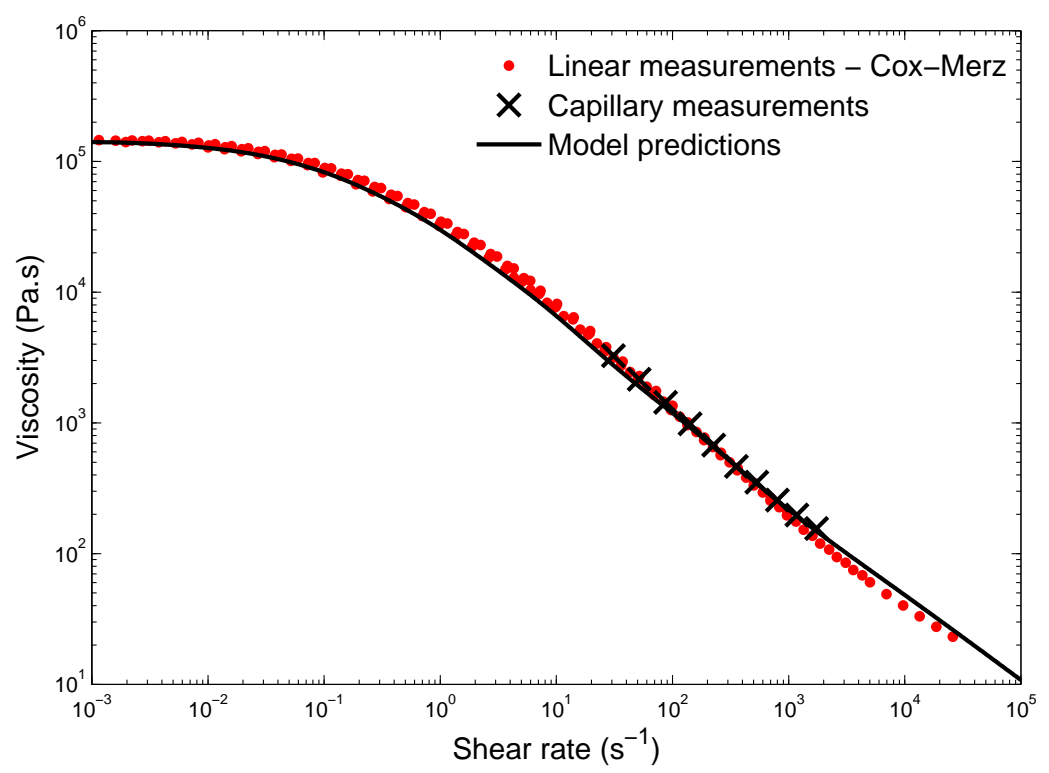

a)

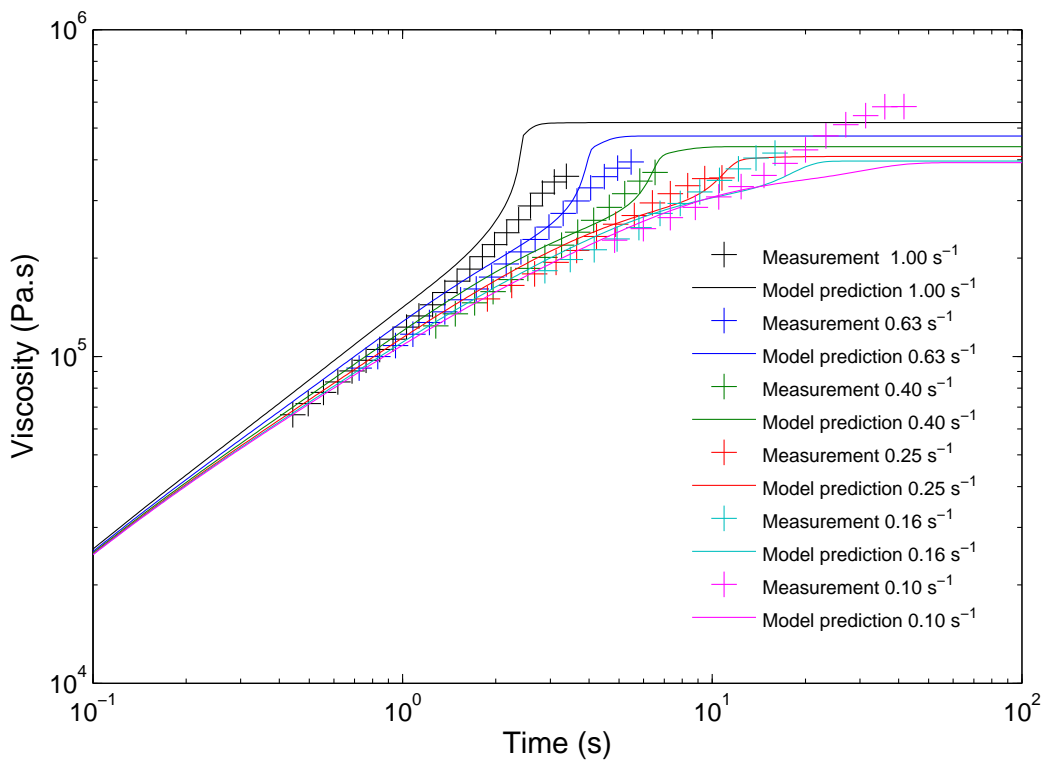

b)

Fig. 5 Second set on non linear parameters $\left(\beta=0.92, b_{i}=(10,10,10,10,10,10,20,30), \theta_{e}=10^{-5} s\right)$, comparison between experimental and computed viscosity: (a) steady shear behaviour, (b) elongational viscosity 


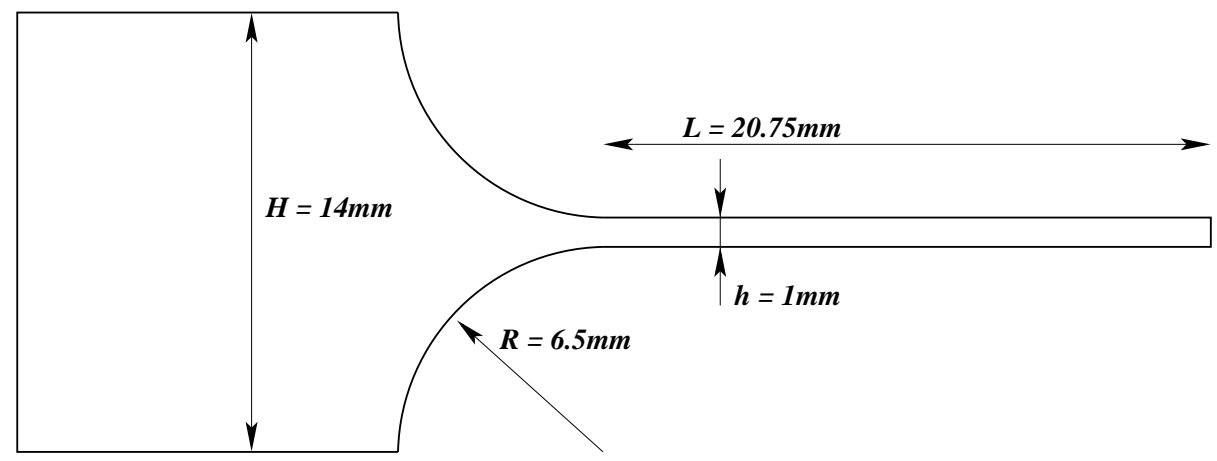

Fig. 6 Geometry of the transparent die

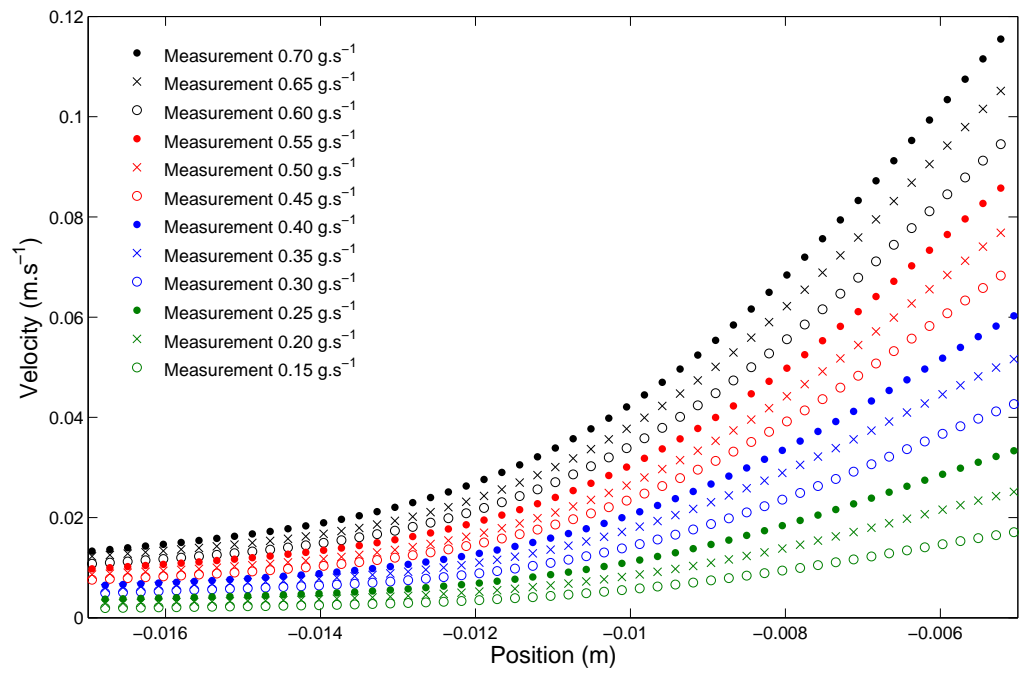

Fig. 7 Velocity field along the flow symmetry axis for various flow rates

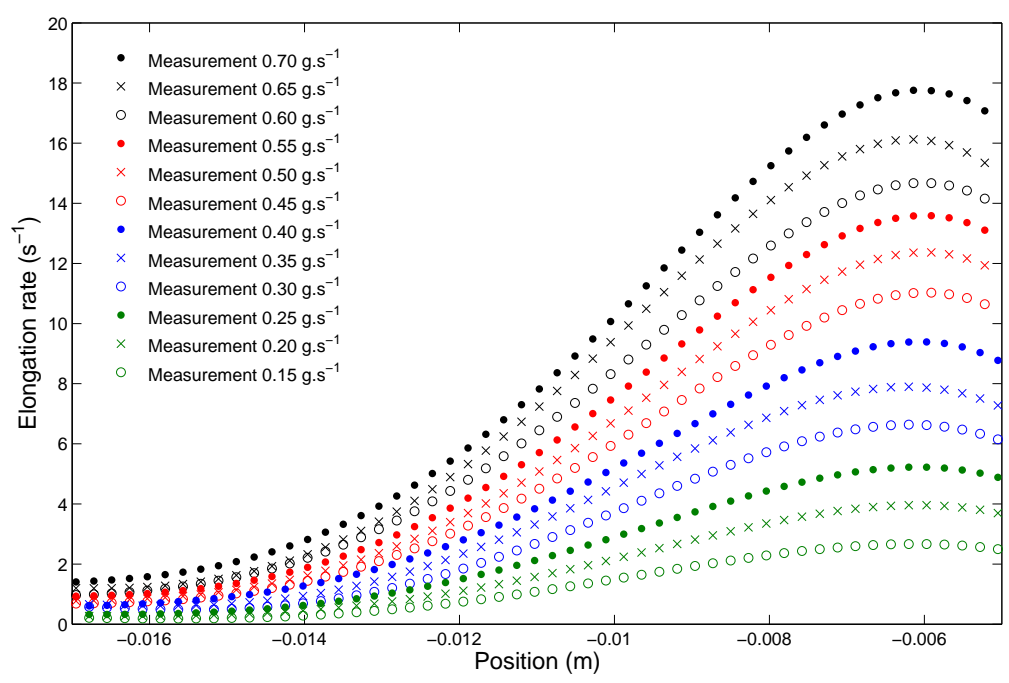

Fig. 8 Planar elongational rate along the flow symmetry axis for various flow rates 


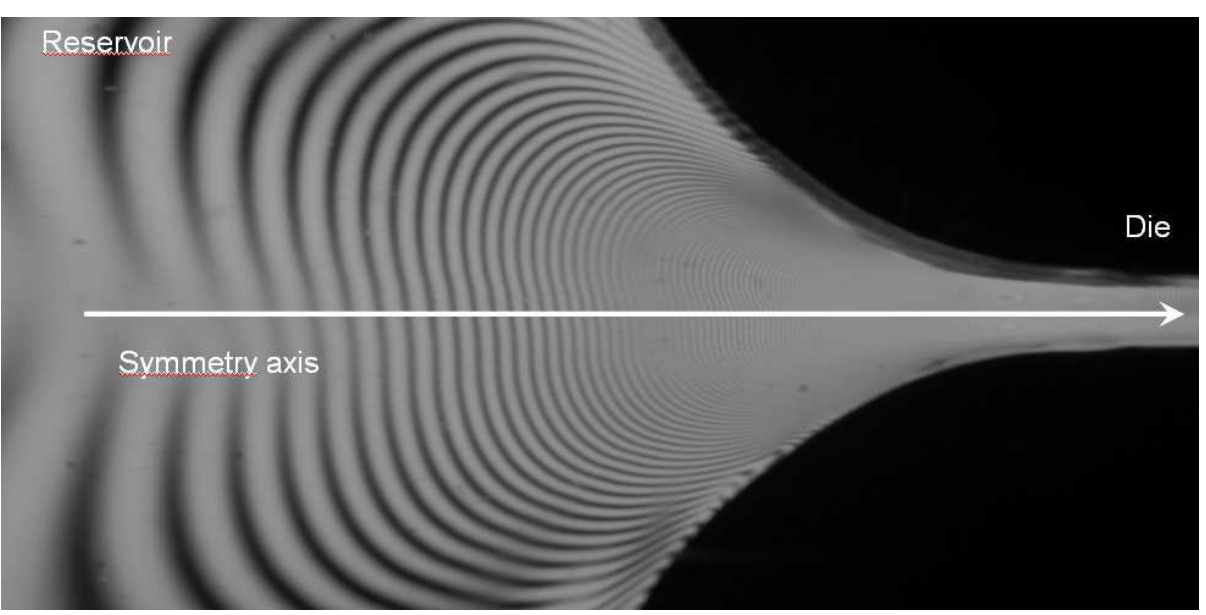

Fig. 9 Typical flow induced birefringence pattern (temperature $180^{\circ} \mathrm{C}$, flow rate $0.25 \mathrm{~g} / \mathrm{s}$ )

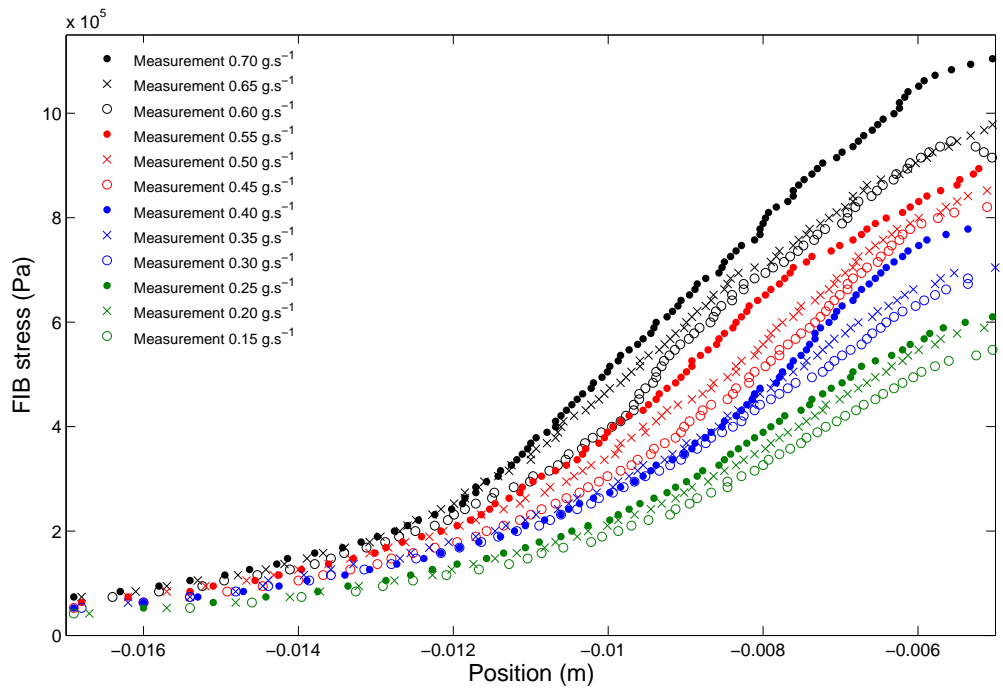

Fig. 10 Elongational stress along the symmetry axis derived from flow induced birefringence experiments at various flow rates 


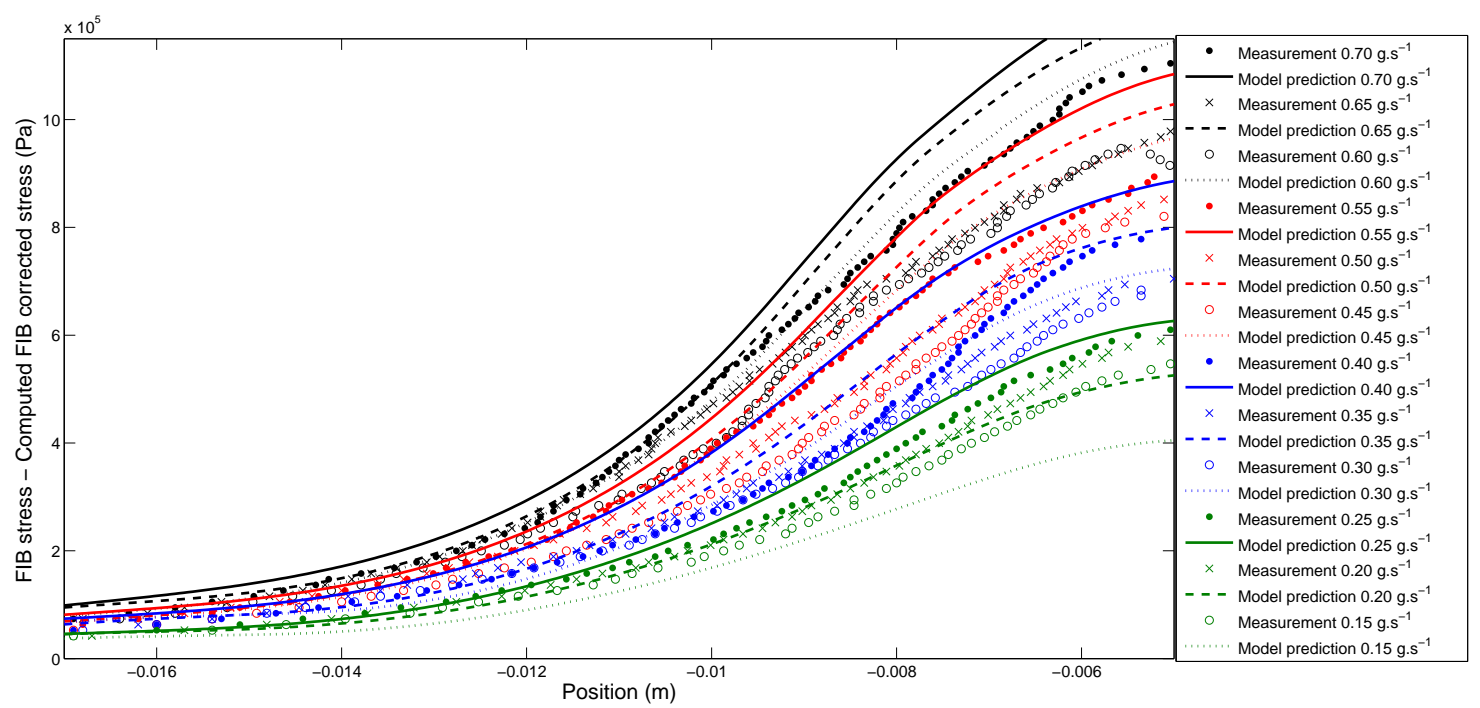

Fig. 11 Comparison of experimental and computed stress field along the symmetry axis using the set of non linear parameters identified previously from rheology data $\left(\beta=0.92, b_{i}=(10,10,10,10,10,10,20,30), \theta_{e}=10^{-5} s\right)$

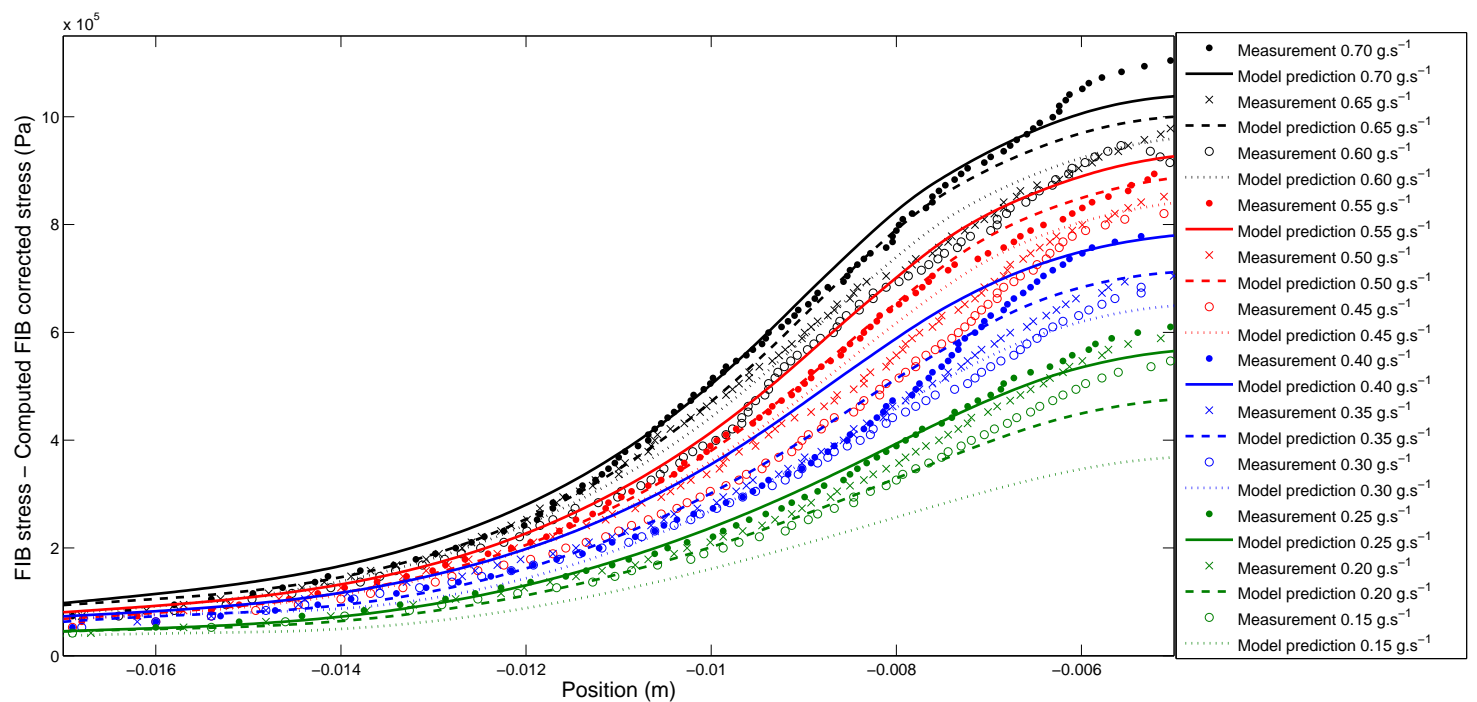

Fig. 12 Comparison of experimental and computed stress field along the symmetry axis using the new set of non linear parameters (table 4) 


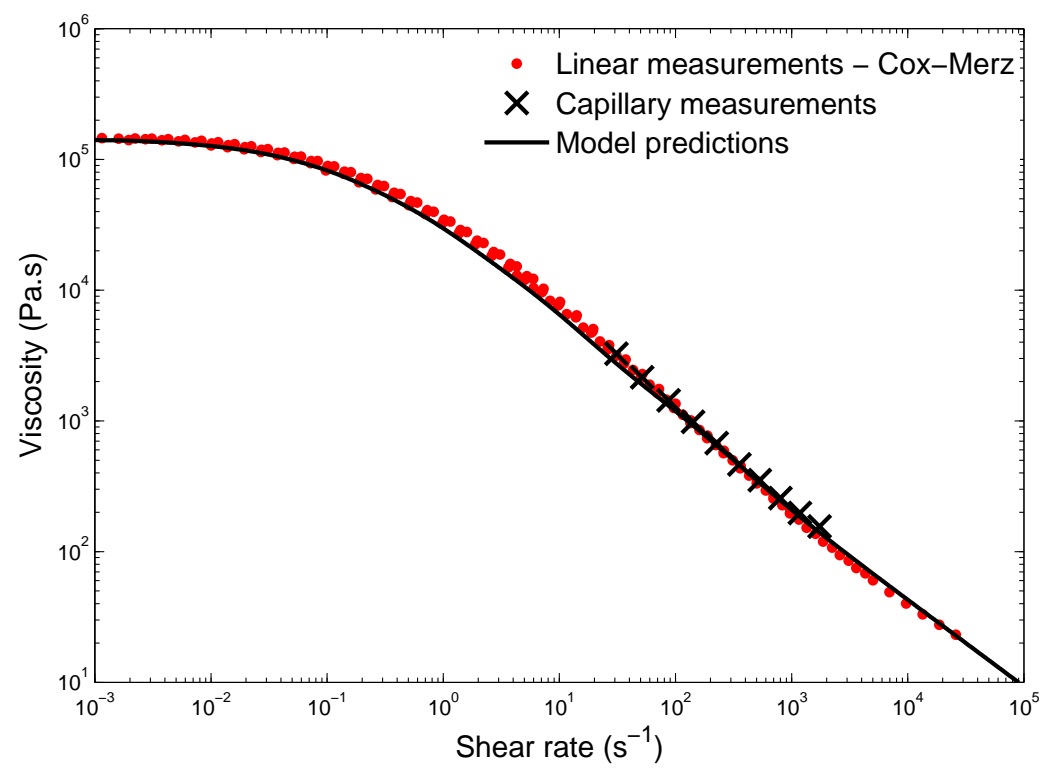

a)

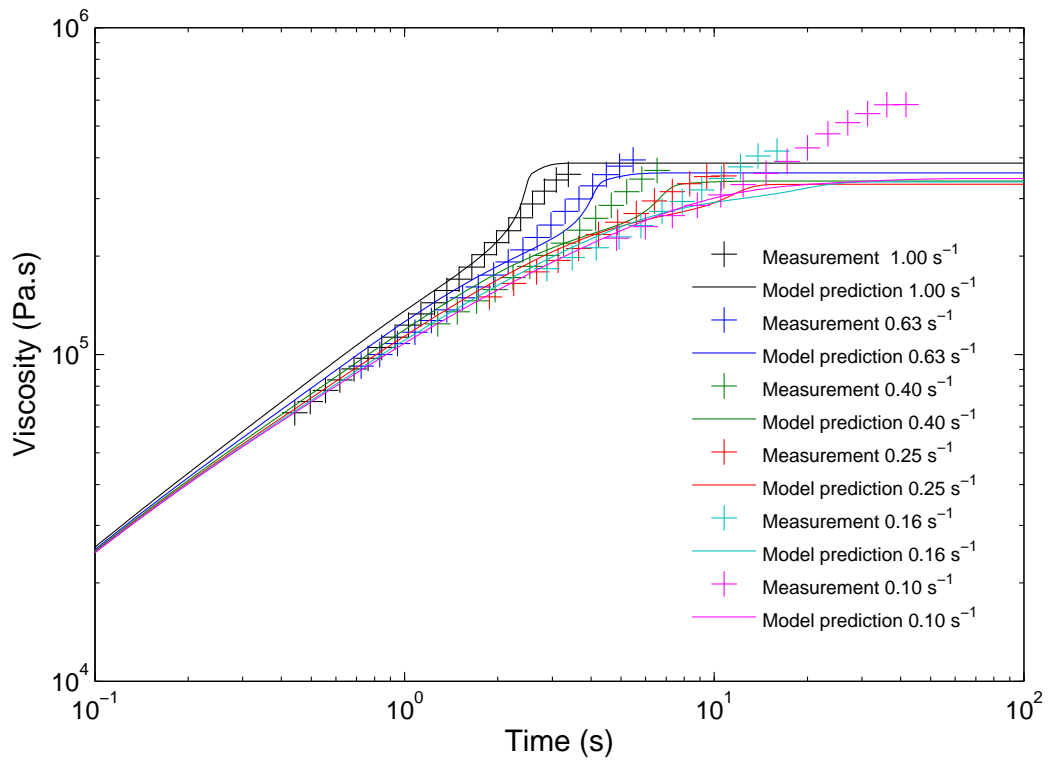

b)

Fig. 13 Comparison between experimental and computed viscosity curves with the new set of non linear parameters (table 4); (a) shear viscosity; (b) elongation viscosity 